\title{
The effect of exacerbation history on outcomes in the IMPACT trial
}

\author{
David M.G. Halpin ${ }^{1}$, Mark T. Dransfield², MeiLan K. Han², C. Elaine Jones ${ }^{4}$, \\ Sally Kilbride ${ }^{5}$, Peter Lange ${ }^{6,7}$, David A. Lipson $\mathbb{1 0}^{8,9}$, David A. Lomas ${ }^{10}$, \\ Fernando J. Martinez ${ }^{11}$, Steve Pascoe ${ }^{8,12}$, Dave Singh ${ }^{13}$, Robert Wise ${ }^{14}$ and \\ Gerard J. Criner ${ }^{15}$
}

\begin{abstract}
Affiliations: 'University of Exeter Medical School, College of Medicine and Health, University of Exeter, Exeter, UK. ${ }^{2}$ Division of Pulmonary, Allergy, and Critical Care Medicine, Lung Health Center, University of Alabama at Birmingham, Birmingham, AL, USA. ${ }^{3}$ University of Michigan, Pulmonary \& Critical Care, Ann Arbor, MI, USA. ${ }^{4}$ GlaxoSmithKline, Research Triangle Park, NC, USA. ${ }^{5}$ GlaxoSmithKline, Stockley Park, UK. ${ }^{6}$ Medical Dept, Herlev and Gentofte Hospital, Herlev, Denmark. ${ }^{7}$ University of Copenhagen, Copenhagen, Denmark. ${ }^{8}$ GlaxoSmithKline, Collegeville, PA, USA. ${ }^{9}$ Perelman School of Medicine, University of Pennsylvania, Philadelphia, PA, USA. ${ }^{10}$ UCL Respiratory, University College London, London, UK. ${ }^{11}$ New York-Presbyterian Hospital/Weill Cornell Medical Center, New York, NY, USA. ${ }^{12}$ Sanofi, Philadelphia, PA, USA. ${ }^{13}$ University of Manchester, NIHR Manchester Biomedical Research Centre, Manchester University NHS Foundation Hospitals Trust, Manchester, UK. ${ }^{14}$ Division of Pulmonary and Critical Care Medicine, Johns Hopkins Medicine, Baltimore, MD, USA. ${ }^{15}$ Lewis Katz School of Medicine at Temple University, Philadelphia, PA, USA.
\end{abstract}

Correspondence: David M.G. Halpin, University of Exeter Medical School, College of Medicine and Health, University of Exeter, Exeter, EX1 2LU, UK. E-mail: d.halpinanhs.net

@ERSpublications

FF/UMEC/VI shows benefits vs FF/VI and UMEC/VI across multiple endpoints irrespective of exacerbation history. Exacerbation history and eosinophils influenced the comparison between UMEC/ VI and FF/VI, and eosinophils that between FF/UMEC/VI and UMEC/VI. http://bit.ly/2SHu2ey

Cite this article as: Halpin DMG, Dransfield MT, Han MLK, et al. The effect of exacerbation history on outcomes in the IMPACT trial. Eur Respir J 2020; 55: 1901921 [https://doi.org/10.1183/13993003.01921-2019].

ABSTRACT IMPACT, a 52-week, randomised, double-blind trial, assessed the efficacy and safety of fluticasone furoate/umeclidinium/vilanterol (FF/UMEC/VI) triple therapy versus FF/VI or UMEC/VI in patients with symptomatic COPD and a history of exacerbations.

Subgroup analyses assessed whether the efficacy of FF/UMEC/VI versus FF/VI or UMEC/VI and UMEC/VI versus FF/VI varies according to prior exacerbation history, and the combined effects of exacerbation history and blood eosinophil counts. Three subgroups were defined: single moderate (1 moderate/no severe; $\mathrm{n}=3056(30 \%))$, frequent moderate $(\geqslant 2$ moderate/no severe; $\mathrm{n}=4628(45 \%)$ ) and severe $(\geqslant 1$ severe/any moderate; $n=2671(26 \%))$. End-points included annual on-treatment moderate/ severe exacerbation rate (pre-specified), lung function and health status (both post-hoc).

Moderate/severe exacerbation rates (reduction \% (95\% CI)) were reduced in the FF/UMEC/VI group versus FF/VI (single moderate 20\% (10-29), frequent moderate $11 \%(2-19)$, severe $17 \%(7-26)$ ) and versus UMEC/VI (single moderate 18\% (5-29), frequent moderate 29\% (21-37), severe 26\% (14-35)). Moderate/ severe exacerbation rates were reduced in the FF/VI group versus UMEC/VI in the frequent moderate subgroup; a numerical reduction was observed in the severe subgroup (single moderate 2\% (-12-18), frequent moderate $21 \%(11-29)$, severe $11 \%(-3-22))$. Moderate/severe exacerbation rates were lower in the FF/VI group compared with UMEC/VI in patients with higher eosinophil counts. FF/UMEC/VI improved lung function and health status versus both dual therapies irrespective of exacerbation subgroup. UMEC/VI improved lung function versus FF/VI in all subgroups.

Triple therapy was more effective than dual regardless of exacerbation history, consistent with results in the intent-to-treat population. Comparisons between dual therapies were influenced by prior exacerbation history and eosinophil counts.

Copyright $\odot$ ERS 2020. This article is open access and distributed under the terms of the Creative Commons Attribution Non-Commercial Licence 4.0. 


\section{Introduction}

Pharmacological treatment of patients with COPD aims to reduce symptoms, improve health status and reduce exacerbations [1, 2]. The ECLIPSE (https://clinicaltrials.gov NCT00292552) and SPIROMICS (https://clinicaltrials.gov NCT01969344) studies have shown that future exacerbation risk is best predicted by history of prior exacerbations [3-5]. In ECLIPSE, patients with one or two exacerbations in the previous year had a two- or five-fold increased risk of exacerbation in the subsequent year, respectively [4]. The 2019 Global Initiative for Chronic Obstructive Lung Disease (GOLD) report recommends assessing exacerbation risk based on patients' prior 12 -month history of exacerbations, with $\geqslant 2$ moderate or 1 severe exacerbation used to predict those at higher risk $[1,6]$.

Analyses from randomised clinical trials in COPD patients with a history of exacerbations have shown that blood eosinophil counts predict inhaled corticosteroid (ICS) effects on exacerbation prevention [7-10]. GOLD recommends blood eosinophils as a biomarker to help guide ICS use, with lower counts $\left(<100\right.$ eosinophils $\left.\mu \mathrm{L}^{-1}\right)$ suggesting a low probability of treatment benefit and higher counts (>300 eosinophils $\mu \mathrm{L}^{-1}$ ) suggesting a high probability [6].

The IMPACT (Informing the Pathway of COPD Treatment) trial evaluated once-daily single-inhaler triple therapy with the ICS fluticasone furoate (FF), the long-acting muscarinic antagonist (LAMA) umeclidinium (UMEC), and the long-acting $\beta_{2}$-agonist (LABA) vilanterol (VI), compared with dual therapies FF/VI and UMEC/VI in patients with symptomatic COPD at increased exacerbation risk [11, 12]. The magnitude of benefit of triple therapy and FF/VI in reducing exacerbation rates compared with UMEC/VI increased with higher blood eosinophil counts [13].

Some analyses have reported the effect of prior exacerbation history on exacerbation outcomes following treatment with LAMA/LABA versus ICS/LABA [14], or with ICS/LAMA/LABA single-inhaler triple therapy versus ICS/LABA or LAMA monotherapy [15-17]. However, these studies included a limited number of patients at high risk of exacerbations (at least two in prior year). Post-hoc analyses have also suggested that there is an interaction between prior exacerbation history and blood eosinophil counts on exacerbation outcomes $[18,19]$. IMPACT offers the opportunity to evaluate whether pharmacological treatment effects differ in patients with only one moderate compared with several moderate or severe exacerbations in the previous year and to examine the relationship between blood eosinophil counts and pharmacological treatment by exacerbation history in a large group of patients with COPD. In these analyses, we examined whether exacerbation history influenced the relative effect of FF/UMEC/VI compared with FF/VI and UMEC/VI on moderate and severe exacerbations, lung function and health-related quality of life in patients with symptomatic COPD and at risk of exacerbations.

\section{Methods}

\section{Study design}

IMPACT (GSK study CTT116855; https://clinicaltrials.gov NCT02164513) was a phase 3, randomised, double-blind, parallel-group multicentre trial. The primary objective was to evaluate the effects of once-daily FF/UMEC/VI (100/62.5/25 $\mu \mathrm{g})$ versus FF/VI $(100 / 25 \mu \mathrm{g})$ or UMEC/VI $(62.5 / 25 \mu \mathrm{g})$ on the rate of moderate or severe COPD exacerbations over 52 weeks. Each regimen was administered in a single dry-powder inhaler (Ellipta, licensed to the GSK group of companies). Details of the study design, including entry criteria and study protocol, have been reported previously [12].

The primary efficacy outcome was on-treatment annual rate of moderate/severe exacerbations. The two co-primary treatment comparisons were FF/UMEC/VI versus UMEC/VI, and FF/UMEC/VI versus FF/VI. Secondary outcomes included time-to-first moderate/severe COPD exacerbation, on-treatment annual rate of severe exacerbation, trough forced expiratory volume in $1 \mathrm{~s}\left(\mathrm{FEV}_{1}\right)$, St George's Respiratory Questionnaire (SGRQ) total score and proportion of SGRQ responders (at least four-unit decrease in SGRQ total score from baseline) at week 52.

These end-points were analysed according to patient exacerbation history in the 12 months prior to screening and were classified into three subgroups: single moderate $(1$ moderate and no severe

This article has been revised according to the erratum published in the June 2020 issue of the European Respiratory Journal.

This article has an editorial commentary https://doi.org/10.1183/13993003.00881-2020

This article has supplementary material available from erj.ersjournals.com

This work is a subanalysis of randomised controlled trial NCT02164513. Anonymised individual participant data and study documents can be requested for further research from www.clinicalstudydatarequest.com

Received: 27 Sept 2019 | Accepted after revision: 17 Feb 2020 
exacerbation), frequent moderate ( $\geqslant 2$ moderate, no severe) and severe ( $\geqslant 1$ severe exacerbation regardless of number of moderate).

Throughout the study, COPD exacerbation severity was categorised as mild, moderate or severe. Mild exacerbations were events not treated with corticosteroids or antibiotics, moderate exacerbations required treatment with systemic corticosteroids and/or antibiotics, and severe exacerbations resulted in hospitalisation or death.

Institutional review boards for human studies at each clinical site approved the protocol and written informed consent was obtained from each patient.

\section{Patients}

Enrolled patients were aged $\geqslant 40$ years with symptomatic COPD: COPD Assessment Test score $\geqslant 10$ (range 0-40) with higher scores indicating more symptoms; minimal clinically important difference (MCID) two units [20]. Patients had to have either a $\mathrm{FEV}_{1}<50 \%$ of predicted with $\geqslant 1$ moderate or severe exacerbations in the prior year, or $\mathrm{FEV}_{1}$ of 50 to $<80 \%$ of predicted and $\geqslant 2$ moderate or $\geqslant 1$ severe exacerbations in the prior year. Patients continued to take their maintenance medication during a 2-week run-in period before randomisation.

\section{Statistical analyses}

Analyses were performed on the intent-to-treat population that comprised all randomised patients $(n=10$ 355), excluding those who were randomised in error who did not receive a dose of study medication $(\mathrm{n}=12)$. Patients were randomised in a $2: 2: 1$ ratio to receive FF/UMEC/VI $(\mathrm{n}=4151), \mathrm{FF} / \mathrm{VI}(\mathrm{n}=4134)$ or UMEC/VI $(\mathrm{n}=2070)$.

The annual rate of on-treatment moderate/severe exacerbations and severe exacerbations was analysed using a generalised linear model assuming a negative binomial distribution with covariates of treatment group, sex, smoking status at screening, geographical region and post-bronchodilator $\mathrm{FEV}_{1} \%$ predicted at screening.

Time-to-first exacerbation end-points were analysed using a Cox proportional hazards model with the same covariates as the annual rate end-points.

Change from baseline in trough $\mathrm{FEV}_{1}$ and SGRQ total score were analysed using mixed repeated measures models with covariates of treatment group, smoking status at screening, geographical region, visit, relevant end-point at baseline, baseline by visit and treatment group by visit interactions.

Proportions of SGRQ responders were analysed using a generalised linear mixed model with a logit link function and covariates of treatment group, smoking status at screening, geographical region, visit, SGRQ total score at baseline, baseline by visit and treatment group by visit interactions.

We used fractional polynomials to model continuous blood eosinophil counts [13] and plotted the selected best-fitting model as continuous eosinophil count versus exacerbation rate in each treatment group for each of the prior exacerbation subgroups. Moderate and severe exacerbation rates on each treatment in each subgroup were also calculated by quintiles of eosinophil counts $(<90,90-<140,140-<200,200-<310$, $\geqslant 310$ cells $\mu \mathrm{L}^{-1}$.)

Analyses were performed for each subgroup separately. Analysis of on-treatment moderate/severe exacerbation rates by exacerbation history subgroup was prespecified; all other analyses performed on these subgroups were post-hoc.

\section{Results}

\section{Patient population}

Baseline demographics were similar across the different subgroups (table 1) and in subgroups by treatment assignment (supplementary table 1). There were differences in the severity of airflow obstruction across the three subgroups. The single moderate subgroup had a lower mean $\mathrm{FEV}_{1}$ predicted and lower mean $\mathrm{FEV}_{1} /$ forced vital capacity ratio than the other two subgroups, reflecting the inclusion criteria (table 1). More patients in the severe subgroup were on triple therapy at enrolment. There were no meaningful differences in baseline characteristics or prior medication use between treatment arms in each prior exacerbation subgroup.

\section{Association between prior exacerbation history, blood eosinophil count and exacerbation outcomes}

There appeared to be a possible association between prior exacerbation history and the number of exacerbations patients experienced during the study. The severe subgroup had a slightly greater proportion of patients having at least three on-treatment moderate or severe exacerbations compared with the other subgroups (figure 1). 
TABLE 1 Baseline demographics according to exacerbation history in the year prior to screening

\begin{tabular}{|c|c|c|c|}
\hline & \multicolumn{3}{|c|}{ Subgroup } \\
\hline & $\begin{array}{l}\text { Single } \\
\text { moderate }\end{array}$ & $\begin{array}{l}\text { Frequent } \\
\text { moderate }\end{array}$ & Severe \\
\hline Subjects & $3056(30)$ & $4628(45)$ & $2671(26)$ \\
\hline Age years & $65.2 \pm 7.95$ & $65.3 \pm 8.46$ & $65.4 \pm 8.29$ \\
\hline Male & 2069 (68) & 2922 (63) & 1879 (70) \\
\hline White & 2408 (79) & 3604 (78) & $1971(74)$ \\
\hline Former smoker & $1964(64)$ & 3014 (65) & $1790(67)$ \\
\hline $\mathrm{BMI} \mathrm{kg} \cdot \mathrm{m}^{-2}$ & $26.10 \pm 6.043$ & $27.03 \pm 5.833$ & $26.52 \pm 6.532$ \\
\hline \multicolumn{4}{|c|}{ Lung function post-bronchodilator } \\
\hline At screening $\mathrm{FEV}_{1} \mathrm{~L}$ & $1.046 \pm 0.3193$ & $1.437 \pm 0.5036$ & $1.247 \pm 0.5037$ \\
\hline $\mathrm{FEV}_{1} \%$ predicted & $37.0 \pm 8.85$ & $51.9 \pm 14.77$ & $44.4 \pm 15.25$ \\
\hline $\mathrm{FEV}_{1} / \mathrm{FVC}$ ratio & $0.421 \pm 0.1028$ & $0.510 \pm 0.1161$ & $0.458 \pm 0.1201$ \\
\hline \multicolumn{4}{|c|}{$\begin{array}{l}\text { Baseline }{ }^{\#} \text { concomitant COPD medication at screening alone } \\
\text { or in combination }\end{array}$} \\
\hline LAMA & $243(8)$ & $375(8)$ & $213(8)$ \\
\hline LABA & $84(3)$ & $166(4)$ & $41(2)$ \\
\hline LAMA+LABA & $327(11)$ & $392(8)$ & $215(8)$ \\
\hline$I C S+L A B A$ & $906(30)$ & 1694 (37) & $741(28)$ \\
\hline$I C S+L A M A+L A B A$ & $1258(41)$ & $1651(36)$ & $1274(48)$ \\
\hline \multicolumn{4}{|c|}{ Baseline blood eosinophil counts } \\
\hline & $203 \pm 186$ & $230 \pm 256$ & $232 \pm 242$ \\
\hline \multicolumn{4}{|l|}{ Patients with count $\%$} \\
\hline$<100$ & 26 & 25 & 24 \\
\hline $100-300$ & 55 & 53 & 52 \\
\hline$>300$ & 19 & 23 & 23 \\
\hline
\end{tabular}

Date are presented as $\mathrm{n}(\%)$ or mean $\pm \mathrm{SD}$, unless otherwise stated. The exacerbation history subgroups are defined as single moderate (1 moderate/no severe exacerbation in the prior year), frequent moderate $(\geqslant 2$ moderate/no severe exacerbations in the prior year) and severe $(\geqslant 1$ severe/any moderate exacerbation in the prior year). BMI: body mass index; $\mathrm{FEV}_{1}$ : forced expiratory volume in $1 \mathrm{~s}$; FVC: forced vital capacity; ICS: inhaled corticosteroid; LABA: long-acting $\beta_{2}$-agonist; LAMA: long-acting muscarinic antagonist. \#: between day of screening -3 days and date of screening (inclusive).

The proportion of patients having just one moderate exacerbation during the study was similar across all three exacerbation history subgroups (40-46\%) and was not affected by treatment (table 2). In contrast, over twice as many patients in the severe subgroup experienced an on-treatment severe exacerbation compared with patients in the single moderate or frequent moderate subgroups (20-23\% versus 6-10\%).

In the frequent moderate subgroup, the proportion of patients who experienced on-treatment severe exacerbations was lower for FF/UMEC/VI and FF/VI (6\% and 7\%, respectively) versus UMEC/VI (10\%) (table 2).

\section{Single moderate subgroup}

In the single moderate subgroup, patients treated with FF/UMEC/VI had a significantly lower annual rate of on-treatment moderate/severe exacerbations versus those treated with FF/VI (rate ratio (95\% CI) 0.80 (0.71-0.90)) and UMEC/VI (rate ratio (95\% CI) $0.82(0.71-0.95)$ ). The model estimated annual rate of on-treatment moderate/severe exacerbations was similar in patients treated with UMEC/VI (1.03 (0.921.16)) and FF/VI (1.06 (0.97-1.15)) (figure 2a). Patients treated with FF/UMEC/VI also had a significantly lower risk of a moderate/severe exacerbation compared with those who received FF/VI (HR (95\% CI) 0.81 $(0.72-0.91)$ ) (figure 3a). The risk reduction point estimates favoured FF/UMEC/VI over UMEC/VI (HR (95\% CI) $0.92(0.79-1.06)$ ) and UMEC/VI over FF/VI but were not significant (HR (95\% CI) 0.88 (0.76-1.02)) (figure 3a).

There were no statistically significant differences in annual rate of on-treatment severe exacerbations with patients treated with FF/UMEC/VI versus those treated with UMEC/VI or FF/VI (figure 2b). The proportion of patients experiencing a severe exacerbation was $9 \%$ for all three treatment arms and there was no difference in the risk when comparing FF/UMEC/VI with FF/VI (HR (95\% CI) 0.99 (0.76-1.28)) or UMEC/VI (1.00 (0.72-1.38)) (figure 3b). 


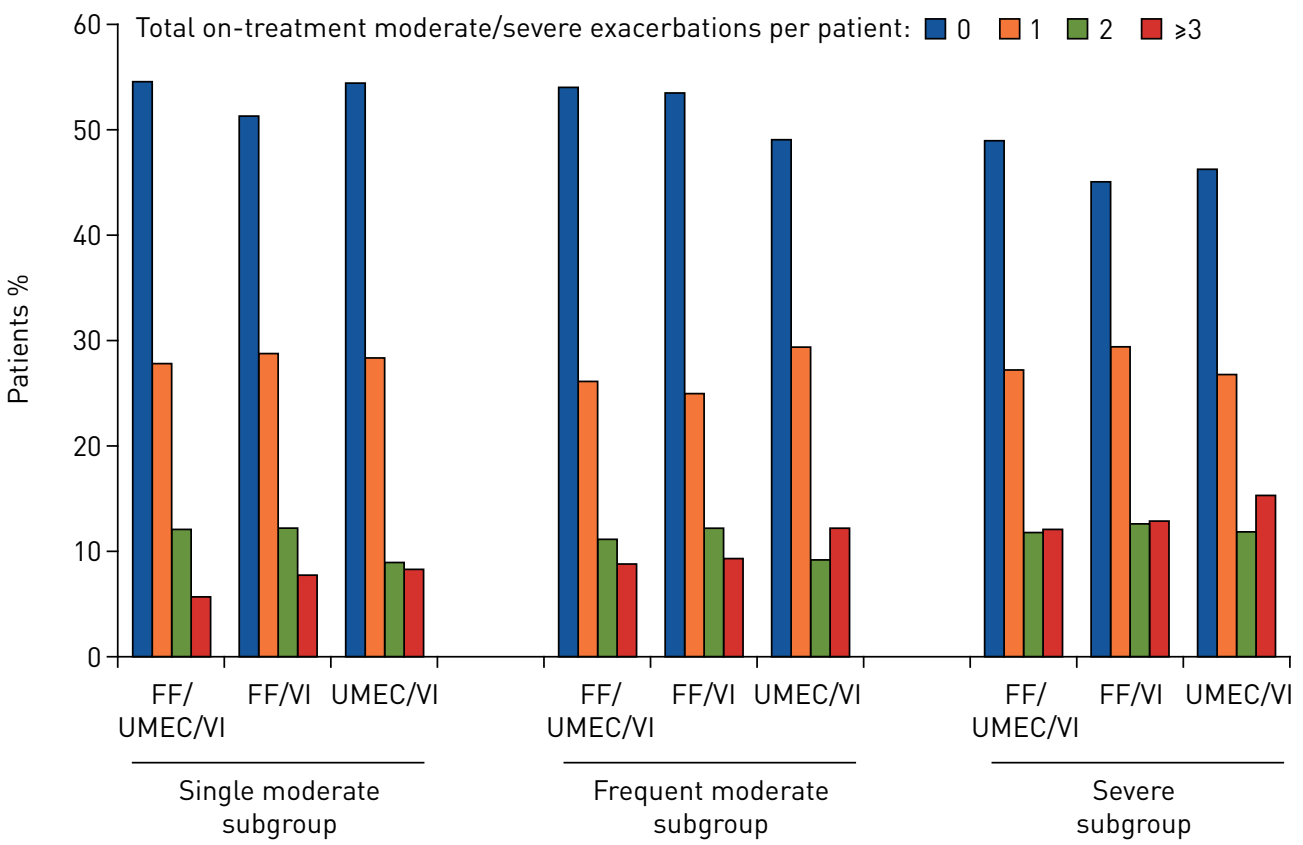

FIGURE 1 Number of combined moderate or severe COPD exacerbations per patient by prior exacerbation subgroup. The exacerbation history subgroups are defined as single moderate 11 moderate/no severe exacerbation in the prior year), frequent moderate $(\geqslant 2$ moderate/no severe exacerbations in the prior yearl and severe $(\geqslant 1$ severe/any moderate exacerbation in the prior year). FF: fluticasone furoate; UMEC: umeclidinium; VI: vilanterol.

When modelled according to blood eosinophil counts, exacerbation rates in the three treatment groups were similar at counts below $\sim 200$ cells $\mu \mathrm{L}^{-1}$ (figure $4 \mathrm{a}$ ). Rates were lower in the FF/UMEC/VI treatment group compared with the UMEC/VI treatment group at higher eosinophil counts: the rates of moderate/ severe exacerbations were 0.88 (95\% CI 0.73-1.05) for FF/UMEC/VI and 0.95 (0.74-1.22) for UMEC/VI at counts 140 to $<200$ cells $\mu \mathrm{L}^{-1}, 0.76(0.64-0.92)$ for FF/UMEC/VI and $1.03(0.81-1.30)$ for UMEC/VI at 200 to $<310$ cells $\mu \mathrm{L}^{-1}$ and $1.08(0.89-1.32)$ for FF/UMEC/VI and $1.21(0.93-1.57)$ for UMEC/VI at counts $\geqslant 310$ cells $\mu \mathrm{L}^{-1}$ (supplementary table 2 ). For FF/VI compared to UMEC/VI, the modelled mean values suggest lower exacerbation rates for patients treated with UMEC/VI at low eosinophil counts, and

TABLE 2 Patients with $\geqslant 1$ moderate, $\geqslant 1$ severe and $\geqslant 1$ moderate or severe on-treatment exacerbations during the study period by exacerbation history in the year prior to screening

On-treatment COPD exacerbations

\begin{tabular}{|c|c|c|c|c|c|}
\hline \multicolumn{2}{|c|}{ Moderate only } & \multicolumn{2}{|c|}{ Severe only } & \multicolumn{2}{|c|}{ Moderate or severe } \\
\hline $486(41)$ & $708.1[750]$ & $112(9)$ & $121.8[129]$ & $545(45)$ & 829.9 [879] \\
\hline 797 (43) & 805.4 [1368] & $117(6)$ & $77.7[132]$ & $859(46)$ & $883.1[1500]$ \\
\hline $436(40)$ & 783.7 [750] & $218(20)$ & 312.4 [299] & $555(51)$ & 1096.1 [1049] \\
\hline $542(44)$ & $857.8[870]$ & $108(9)$ & $135.1[137]$ & 605 (49) & 992.9 [1007] \\
\hline $799(44)$ & $882.2[1384]$ & $120(7)$ & $89.2[140]$ & $847(46)$ & 971.4 [1524] \\
\hline $454(42)$ & $914.4[800]$ & $233(22)$ & $348.6[305]$ & $587(55)$ & $1263.0[1105]$ \\
\hline $252(41)$ & 849.1 [429] & $55(9)$ & $120.7[61]$ & $281(46)$ & $969.9[490]$ \\
\hline $430(46)$ & 1002.1 [790] & $96(10)$ & $145.9[115]$ & $478(51)$ & 1147.9 [905] \\
\hline $205(40)$ & 958.8 [388] & $121(23)$ & $410.2[166]$ & $277(54)$ & $1369.0[554]$ \\
\hline
\end{tabular}

\section{FF/UMEC/VI}

Single moderate

Frequent moderate

Severe

\section{FF/VI}

Single moderate

Frequent moderate

Severe

UMEC/VI

Single moderate

Frequent moderate

Severe
$542(44)$

799 (44)

205 (40)
277 (54)
829.9 [879]

883.1 [1500]

992.9 [1007]

$971.4[1524]$

969.9 [490]

1369.0 [554]

Data are presented as $\mathrm{n}(\%)$ or rate [number of events]. Rate is reported per 1000 subject-years, calculated as the number of events $\times 1000$ divided by the total duration at risk. The exacerbation history subgroups are defined as single moderate $(1$ moderate/no severe exacerbation in the prior year), frequent moderate ( $\geqslant 2$ moderate/no severe exacerbations in the prior year) and severe ( $\geqslant 1$ severe/any moderate exacerbation in the prior year). FF: fluticasone furoate; UMEC: umeclidinium; VI: vilanterol. 
a)

FF/UMEC/VI versus FF/VI

Single moderate subgroup

Frequent moderate subgroup

Severe subgroup

FF/UMEC/VI versus UMEC/VI

Single moderate subgroup

Frequent moderate subgroup

Severe subgroup

UMEC/VI versus $\mathrm{FF} / \mathrm{VI}$

Single moderate subgroup

Frequent moderate subgroup

Severe subgroup
Treatment A FF/UMEC/VI

$0.85(0.78-0.92)$

$0.85(0.80-0.91)$

$1.06(0.98-1.16)$

FF/UMEC/VI

$0.85(0.78-0.92)$

$1.06(0.98-1.16)$

UMEC/VI

$1.03(0.92-1.16)$

$1.21(1.10-1.32)$

$1.43(1.27-1.61)$
$0.85(0.80-0.91)$

\section{Treatment B \\ FF/VI}

$1.06(0.97-1.15)$

$0.96(0.90-1.03)$

$1.28(1.18-1.39)$

UMEC/VI

$1.03(0.92-1.16)$

$1.21(1.10-1.32)$

$1.43(1.27-1.61)$

FF/VI

$1.06(0.97-1.15)$

$0.96(0.90-1.03)$

$1.28(1.18-1.39)$
$\operatorname{RR}(95 \%$ Cl $)$

$0.80(0.71-0.90)$

$0.89(0.81-0.98)$

$0.83(0.74-0.93)$

$0.82(0.71-0.95)$

$0.71(0.63-0.79)$

$0.74(0.65-0.86)$

$0.98(0.85-1.13)$

$1.26(1.12-1.41)$

$1.12(0.97-1.29)$ p-value

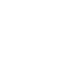

$<0.001$
0.016

0.002

0.007

$<0.001$

$<0.001$

0.782
$<0.001$

$<0.001$
Favours Favours Treatment A Treatment B

b)

\section{Treatment A FF/UMEC/VI}

\section{Treatment B FF/VI}

\section{FF/UMEC/VI versus FF/VI}

Single moderate subgroup

Frequent moderate subgroup

Severe subgroup

$0.11(0.09-0.14)$

$0.06(0.05-0.08)$

$0.29(0.25-0.33)$

$\mathrm{FF} / \mathrm{UMEC} / \mathrm{VI}$ versus UMEC/VI FF/UMEC/VI

Single moderate subgroup $\quad 0.11(0.09-0.14)$

Frequent moderate subgroup $0.06(0.05-0.08)$

Severe subgroup

$0.29(0.25-0.33)$

UMEC/VI versus $\mathrm{FF} / \mathrm{VI}$

UMEC/VI

Single moderate subgroup $\quad 0.11(0.08-0.15)$

Frequent moderate subgroup $0.14(0.11-0.17)$

Severe subgroup

$0.42(0.34-0.51)$
$0.13(0.10-0.16)$

$0.07(0.06-0.09)$

$0.33(0.28-0.38)$

\section{UMEC/VI}

$0.11(0.08-0.15)$

$0.14(0.11-0.17)$

$0.42(0.34-0.51)$

\section{FF/VI}

$0.13(0.10-0.16)$

$0.07(0.06-0.09)$

$0.33(0.28-0.38)$

\section{$\operatorname{RR}(95 \% \mathrm{Cl})$}

$0.88(0.66-1.18)$

$0.84(0.64-1.10)$

$0.88(0.72-1.08)$

$0.99(0.69-1.43)$

$0.45(0.33-0.61)$

$0.69(0.54-0.88)$

$0.89(0.62-1.28)$

$1.86(1.37-2.51)$

$1.28(1.00-1.64)$

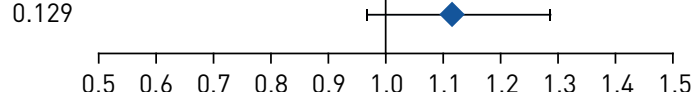

$\operatorname{RR}(95 \% \mathrm{CI})$

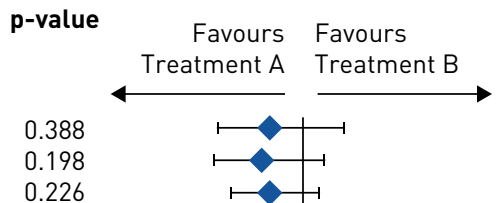

0.226

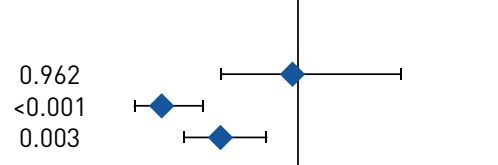

0.003

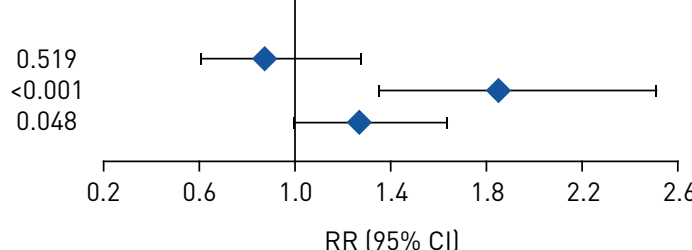

FIGURE 2 Annual rate of on-treatment a) moderate or severe and b) severe exacerbations (post-hoc analysis) according to exacerbation history in the year prior to screening for each treatment comparison. The exacerbation history subgroups are defined as single moderate 11 moderate/no severe exacerbation in the prior year), frequent moderate $(\geqslant 2$ moderate/no severe exacerbations in the prior year) and severe ( 1 severe/any moderate exacerbation in the prior year). Data are presented as model estimated annual rate $(95 \% \mathrm{CI})$, unless otherwise stated. FF: fluticasone furoate; RR: rate ratio; UMEC: umeclidinium; VI: vilanterol.

lower exacerbation rates for those treated with FF/VI at high eosinophil counts, but the confidence intervals were not significant for these numerical trends (figure $5 \mathrm{a}$ and $\mathrm{b}$ ).

\section{Frequent moderate subgroup}

In the frequent moderate subgroup, the annual rate of on-treatment moderate/severe exacerbations was significantly lower for patients receiving FF/UMEC/VI versus FF/VI (rate ratio (95\% CI) 0.89 (0.81-0.98)) or UMEC/VI $(0.71(0.63-0.79)$ ) (figure $2 \mathrm{a})$, and the risk of a moderate/severe exacerbation was significantly lower for patients receiving FF/UMEC/VI compared with UMEC/VI (HR (95\% CI) 0.80 (0.72-0.90)) (figure 3a). The FF/UMEC/VI treatment group also had a lower annual rate of on-treatment severe exacerbations compared with the UMEC/VI group $(0.45(0.33-0.61))$ (figure $2 b)$. The annual rate and the risk of on-treatment moderate/severe exacerbations was significantly lower in the FF/VI than the UMEC/VI treatment group $(0.79(0.70-0.89)$, HR $(95 \%$ CI) $0.87(0.78-0.98))$ and so was the annual rate of severe exacerbations $(0.53(0.39-0.75))$ (figures 2 and $3 a)$.

Exacerbation rates modelled according to blood eosinophil counts in the three treatment groups were similar at counts below approximately 100 cells $\mu \mathrm{L}^{-1}$ (figure $4 \mathrm{~b}$ ). Above this level, rates were significantly higher in the UMEC/VI treatment group versus FF/UMEC/VI and FF/VI groups (figure $5 \mathrm{~d}$ ) with rates of moderate/severe exacerbations of 0.85 (95\% CI 0.73-0.98), 0.93 (0.81-1.08) and 1.25 (1.04-1.51) for FF/ UMEC/VI, FF/VI and UMEC/VI, respectively, at counts of 200 to $<310$ cells. $\mu \mathrm{L}^{-1}$ and $0.87(0.75-1.01)$, 
a)

FF/UMEC/VI versus FF/VI

Single moderate subgroup

Frequent moderate subgroup

Severe subgroup

FF/UMEC/VI versus UMEC/VI

Single moderate subgroup

Frequent moderate subgroup

Severe subgroup

\section{UMEC/VI versus $\mathrm{FF} / \mathrm{V}$}

Single moderate subgroup

Frequent moderate subgroup

Severe subgroup

b)

FF/UMEC/VI versus FF/V

Single moderate subgroup

Frequent moderate subgroup

Severe subgroup

FF/UMEC/VI versus UMEC/VII

Single moderate subgroup

Frequent moderate subgroup

Severe subgroup

UMEC/VI versus $\mathrm{FF} / \mathrm{VI}$

Single moderate subgroup

Frequent moderate subgroup

Severe subgroup
Treatment A

FF/UMEC/VI

$545 / 1198$ (45)

$859 / 1866(46)$

$555 / 1087$ (51)

FF/UMEC/VI

545/1198 (45)

$859 / 1866(46)$

$555 / 1087$ (51)

UMEC/VI

281/616 (46)

478/939 (51)

277/515 (54)

\section{Treatment B \\ FF/VI}

$605 / 1242$ (49)

$847 / 1823$ (46)

$587 / 1069$ (55)

UMEC/VI

281/616 (46)

478/939 (51)

277/515 (54)

FF/VI

605/1242 (49)

$847 / 1823$ (46)

$587 / 1069$ (55)

$0.88(0.76-1.02)$
$1.14(1.02-1.27)$

$1.00(0.87-1.15)$

$0.92(0.79-1.06)$

$0.80(0.72-0.90)$

$0.81(0.70-0.93)$

0.023

0.991

0.246

$<0.00$

0.003
Favours Favours

Treatment A Treatment B

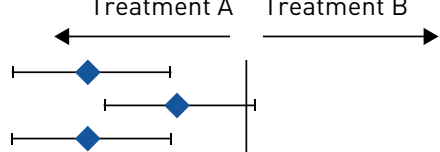

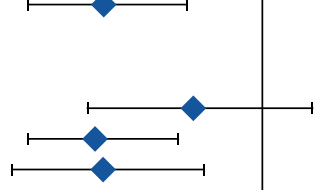

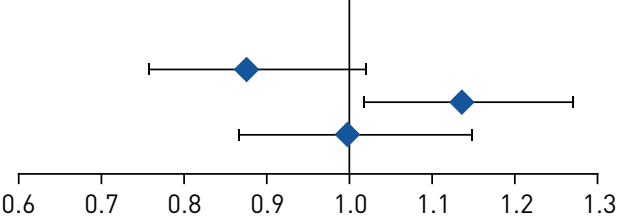

HR (95\% CI)

Treatment B
FF/VI
108/1242 (9)
$120 / 1823$ (7)
$233 / 1069(22)$

UMEC/VI
$55 / 616$ (9)
$96 / 939(10)$
$121 / 515(23)$

FF/VI
$108 / 1242(9)$
$120 / 1823(7)$
$233 / 1069(22)$

$\operatorname{HR}(95 \% \mathrm{CI})$

FF/UMEC/V

$0.99(0.76-1.28)$

$0.88(0.69-1.14)$

$0.83(0.69-1.00)$

$117 / 1866(6)$

218/1087 (20)

FF/UMEC/VI

$112 / 1198$ (9)

$117 / 1866(6)$

218/1087 (20)

UMEC/VI

$55 / 616$ (9)

$96 / 939(10)$

$121 / 515(23)$

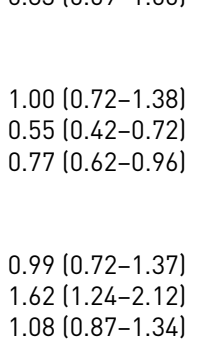

p-value

Favours Favours

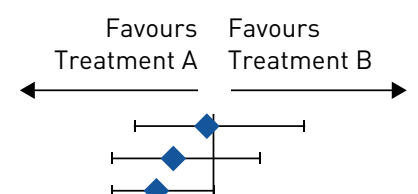

0.050

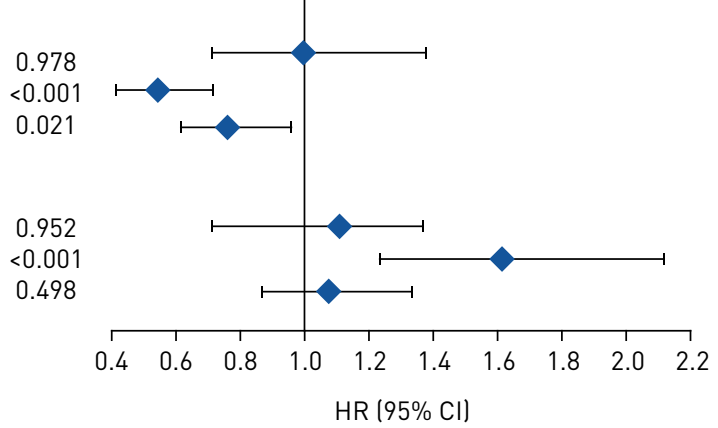

FIGURE 3 Time-to-first combined a) moderate or severe and b) severe COPD exacerbations (post-hoc analysis) by treatment by prior exacerbation subgroup for each treatment comparison. The exacerbation history subgroups are defined as single moderate 11 moderate/no severe exacerbation in the prior year), frequent moderate ( $\geqslant 2$ moderate/no severe exacerbations in the prior year) and severe ( $\geqslant 1$ severe/any moderate exacerbation in the prior year). Data are presented as patients with events $\mathrm{n} / \mathrm{N}(\%)$, unless otherwise stated. FF: fluticasone furoate; UMEC: umeclidinium; VI: vilanterol.

$0.91(0.79-1.06)$ and $2.05(1.70-2.49)$ for FF/UMEC/VI, FF/VI and UMEC/VI, respectively, at counts $\geqslant 310$ cells $\mu \mathrm{L}^{-1}$ (supplementary table 2 ).

\section{Severe subgroup}

In the severe subgroup, patients treated with FF/UMEC/VI had a reduced rate and risk of on-treatment moderate/severe exacerbations versus those treated with FF/VI (rate ratio (95\% CI) 0.83 (0.74-0.93), HR (95\% CI) $0.81(0.72-0.91)$ ) and UMEC/VI (rate ratio (95\% CI) $0.74(0.65-0.86)$, HR (95\% CI) $0.81(0.70-$ $0.93)$ ) and also had a reduced rate of on-treatment severe exacerbations versus those treated with $\mathrm{FF} / \mathrm{VI}$ (rate ratio (95\% CI) $0.88(0.72-1.08)$ ) and UMEC/VI (rate ratio (95\% CI) $0.69(0.54-0.88)$ ) (figures 2 and 3a). The FF/VI treatment group had a greater reduction in the annual rate of severe exacerbations than the UMEC/VI group (rate ratio $(95 \% \mathrm{CI}) 0.78(0.61-1.00)$ ). The point estimate favoured FF/VI over UMEC/VI for moderate/severe exacerbation rates (rate ratio (95\% CI) 0.89 (0.77-1.03)), but there were no differences observed between patients treated with FF/VI and those treated with UMEC/VI on the time-to-first moderate/severe exacerbation (HR (95\% CI) 1.00 (0.86-1.14)) (figures 2 and 3a).

Exacerbation rates modelled according to blood eosinophil counts in the three treatment groups were similar at counts below $\sim 100$ cells $\mu \mathrm{L}^{-1}$ (figure $4 \mathrm{c}$ ). Above this level, the FF/UMEC/VI and FF/VI treatment groups had lower rates than the UMEC/VI group (figure $5 \mathrm{e}$ and $5 \mathrm{f}$ ), with rates of moderate or severe exacerbations of 0.89 (95\% CI 0.73-1.07), 1.35 (1.14-1.59) and 1.42 (1.11-1.80) for FF/UMEC/VI, 
a)

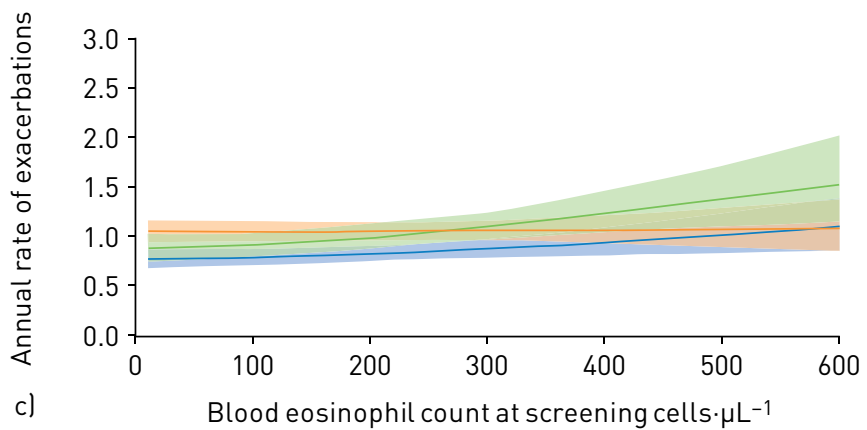

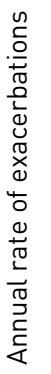

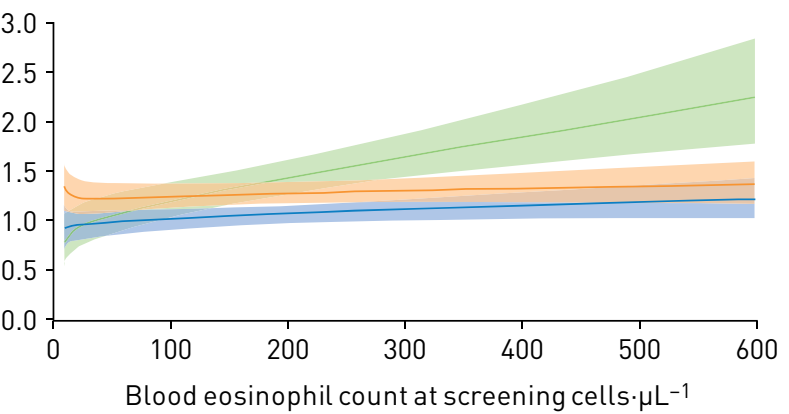

b)

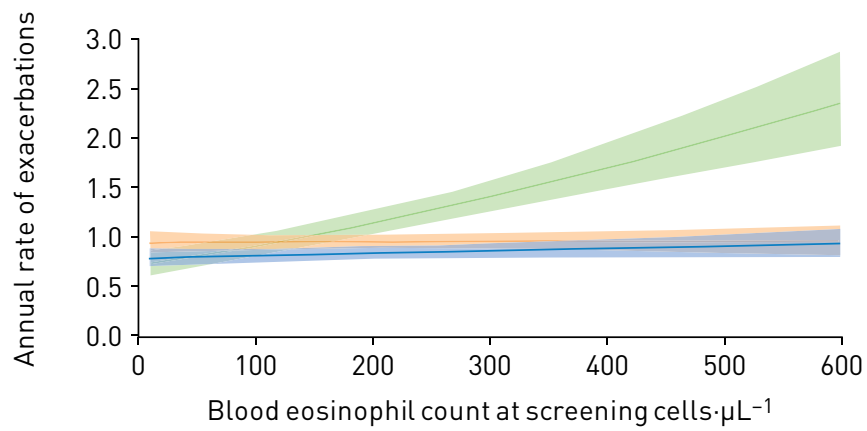

- FF/UMEC/VI
- UMEC/VI
- FF/VI

FIGURE 4 Annual rate of moderate or severe exacerbations, by baseline blood eosinophil count and individual treatment group by prior exacerbation subgroup: a) single moderate, b) frequent moderate and c) severe. The exacerbation history subgroups are defined as single moderate (1 moderate/no severe exacerbation in the prior year), frequent moderate ( $\geqslant 2$ moderate/no severe exacerbations in the prior year) and severe ( $\geqslant 1$ severe/any moderate exacerbation in the prior year). FF: fluticasone furoate; UMEC: umeclidinium; VI: vilanterol.

FF/VI and UMEC/VI, respectively, at counts of 200 to $<310$ cells $\mu \mathrm{L}^{-1}$ and $1.20(1.01-1.43), 1.20(1.00$ $1.44)$ and $2.02(1.59-2.58)$ for FF/UMEC/VI, FF/VI and UMEC/VI, respectively, at counts $\geqslant 310$ cells $^{\prime} \mathrm{L}^{-1}$ (supplementary table 2).

\section{Association between prior exacerbation history and health status}

In all subgroups, the mean change from baseline in SGRQ total score at week 52 for the FF/UMEC/VI treatment group was greater than the MCID (four units) [21], and in each subgroup the improvement in SGRQ total score from baseline was greater in the FF/UMEC/VI treatment group (single: -4.8 , frequent: -6.3, severe: -4.6 ), than the FF/VI (single: -2.4 , frequent: -4.9 , severe: -2.9 ) and UMEC/VI treatment groups (single: -3.0 , frequent: -4.5 , severe: -3.0 ), both of which showed similar effects (figure 6). The mean changes from baseline in SGRQ total score at week 52 for all treatments were greater in the frequent moderate subgroup than the other subgroups. A larger proportion of patients on FF/UMEC/VI had a four-unit change in SGRQ total score at week 52 compared with FF/VI or UMEC/VI, regardless of exacerbation history (supplementary figure 1).

\section{Association between prior exacerbation history and trough FEV 1 during the study}

Mean change from baseline in trough $\mathrm{FEV}_{1}$ at week 52 according to exacerbation history is shown in supplementary figure 2. In all three subgroups, patients treated with FF/UMEC/VI had a significantly improved trough $\mathrm{FEV}_{1}$ compared with those treated with FF/VI (by $\sim 100 \mathrm{~mL}$ ) and UMEC/VI (by 30 to $\sim 70 \mathrm{~mL}$ ). The UMEC/VI treatment group had a greater improvement in trough $\mathrm{FEV}_{1}$ than the FF/VI treatment group (by $27-63 \mathrm{~mL}$ ).

Safety data have been previously published [11]. The safety profile of FF/UMEC/VI was similar to that of FF/VI and UMEC/VI, with no new identified safety signals [11].

\section{Discussion}

These analyses, based on prior exacerbation history, show that in patients with symptomatic COPD and at risk of exacerbations, triple therapy (FF/UMEC/VI) was superior to dual therapy for preventing exacerbations and improving health status and $\mathrm{FEV}_{1}$, regardless of exacerbation history. Analysis based on both prior exacerbation history and blood eosinophil counts showed no significant difference in 

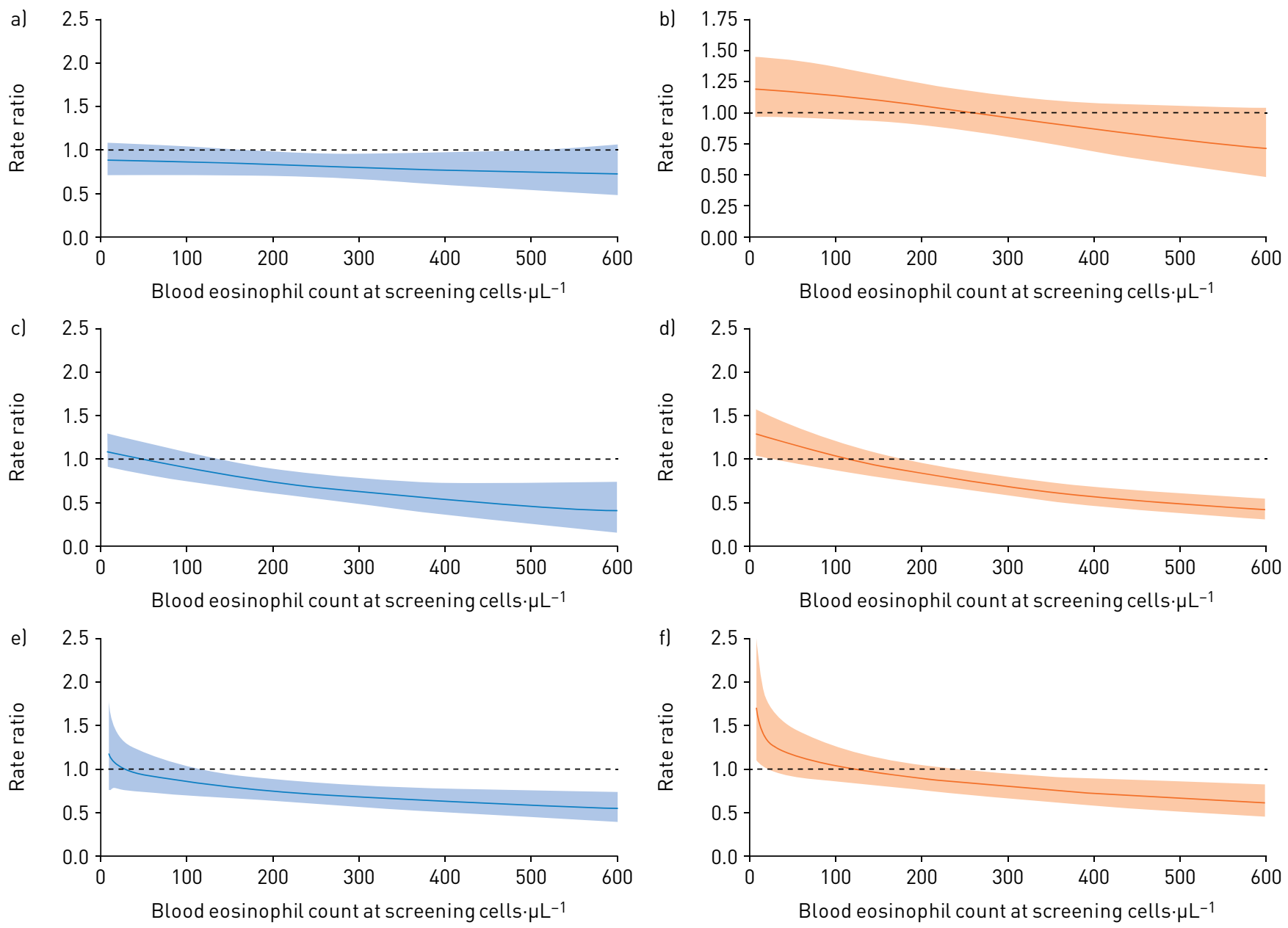

FIGURE 5 Between-treatment differences of $a, c$, e) FF/UMEC/VI versus UMEC/VI and b, d, f) FF/VI versus UMEC/VI in rates of moderate or severe exacerbations, by baseline blood eosinophil count and prior exacerbation subgroup: a, b) single moderate, $c$, d) frequent moderate, e, f) severe. The exacerbation history subgroups are defined as single moderate ( 1 moderate/no severe exacerbation in the prior year), frequent moderate ( $\geqslant 2$ moderate/no severe exacerbations in the prior year) and severe ( $\geqslant 1$ severe/any moderate exacerbation in the prior year). FF: fluticasone furoate; UMEC: umeclidinium; VI: vilanterol.

exacerbation rates with triple therapy compared with dual therapy in patients with lower eosinophil counts irrespective of prior exacerbation history. The comparative effects of LAMA/LABA versus ICS/LABA varied according to previous exacerbation history and were different for different outcomes; importantly, the effects of FF/VI were greater than UMEC/VI only in patients with higher blood eosinophil counts together with either frequent moderate exacerbations or a severe exacerbation in the previous year.

Patients with a history of severe exacerbations in the previous year were more likely to have a severe exacerbation whilst on treatment than patients who only had moderate exacerbations. In the severe subgroup, FF/UMEC/VI was significantly more effective overall than FF/VI and UMEC/VI at reducing the rate of severe exacerbations.

In the subgroup who had a single moderate exacerbation in the previous year, the overall rate of exacerbations with UMEC/VI was lower than with FF/VI, although the difference was not statistically significant. When blood eosinophil counts were considered, there was a trend for patients on UMEC/VI to have higher rates of exacerbations compared with those on FF/VI at higher eosinophil counts, although the differences were not statistically significant, possibly because of lack of power owing to the small size of this subgroup. The patients in this subgroup are similar to those recruited to the FLAME study (NCT01782326), as approximately $80 \%$ had just one exacerbation in the year prior to the study. The effect of LAMA/LABA on exacerbation rates in these patients is in line with the FLAME study results [22]. Indeed, these findings comparing dual combinations in patients with one moderate exacerbation, coupled with the greater effect of ICS/LABA in patients with higher exacerbation risk, are compatible with the GOLD 2019 follow-up recommendations for the prevention of exacerbations. Greater exacerbation risk along with higher blood eosinophil counts favour ICS/LABA rather than LAMA/LABA use $[1,6]$. 


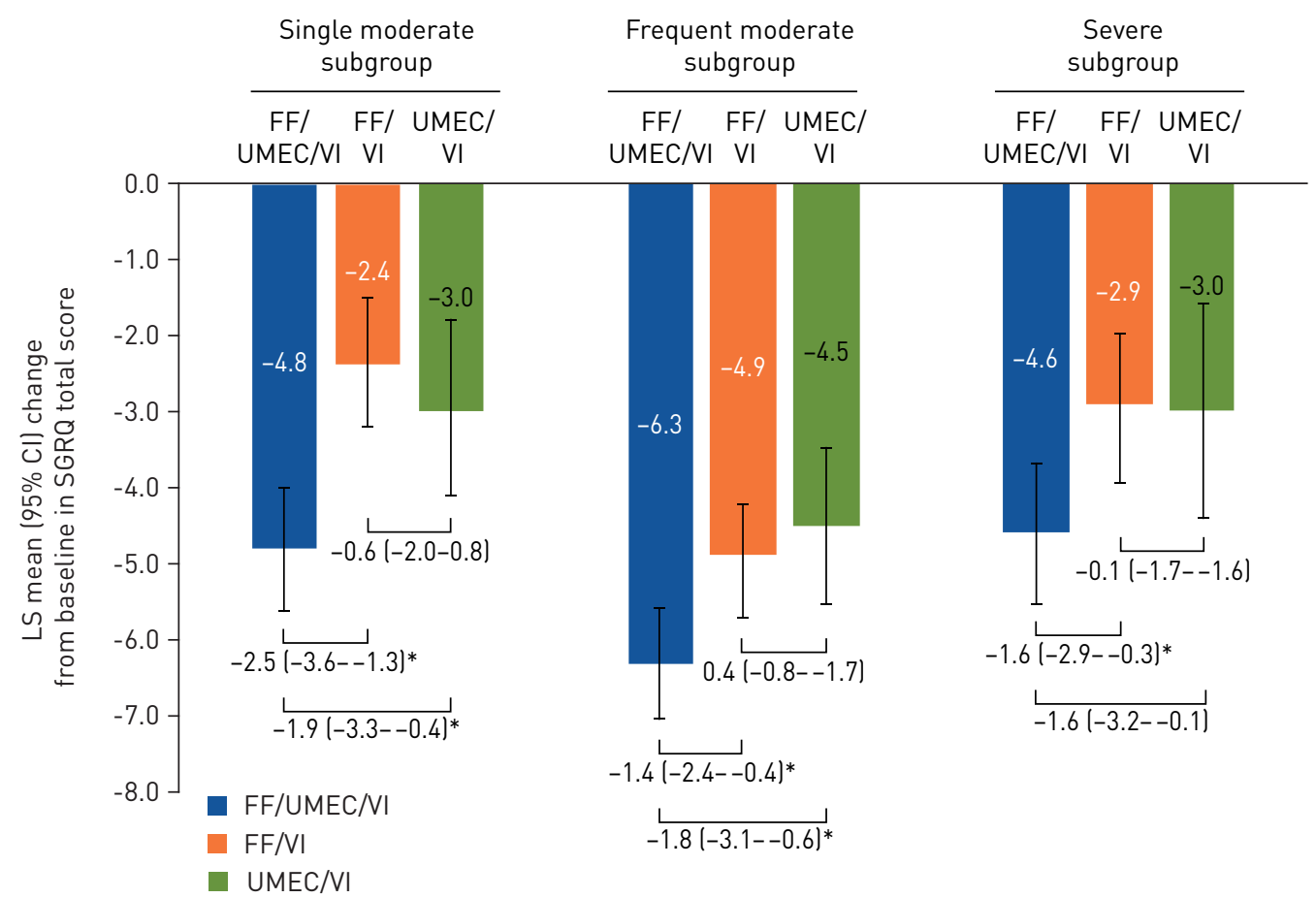

FIGURE 6 LS mean (95\% CI) change in St George's Respiratory Questionnaire (SGRQ) at week 52 by prior exacerbation subgroup. The exacerbation history subgroups are defined as single moderate 11 moderate/no severe exacerbation in the prior year), frequent moderate $1 \geqslant 2$ moderate/no severe exacerbations in the prior year) and severe ( $\geqslant 1$ severe/any moderate exacerbation in the prior year). Post hoc analysis. Data presented as between-treatment difference $(95 \% \mathrm{CI})$ in LS mean change from baseline at week 52 in SGRQ total score for FF/UMEC/VI versus UMEC/VI, FF/UMEC/VI versus FF/VI and UMEC/VI versus FF/VI. FF: fluticasone furoate; LS: least squares; UMEC: umeclidinium; VI: vilanterol. *: $p<0.05$.

The analysis shows differences in both the annual rate of exacerbations and the time-to-first exacerbation. The latter is important clinically because reducing exacerbation risk is an important goal for clinicians and patients. The effect on exacerbation rates reflects reductions in repeated exacerbations during the study and is likely to have contributed to the positive effects seen on health status.

Health status, as measured by SGRQ total score, did not show differential treatment effects by prior exacerbation history; FF/UMEC/VI was the most effective therapy and produced changes in health status greater than the MCID in all three subgroups. The greatest effect was seen in patients with frequent moderate but no severe exacerbations. UMEC/VI had similar effects to FF/VI.

The strengths of the analyses are the study population size, the prospective double-blinded study design comparing FF/UMEC/VI with FF/VI and UMEC/VI, the 52-week study duration, and the completeness and rigor of study end-points collection.

Limitations include the retrospective nature of the subgroup classification and that entry criteria based on exacerbation frequency were confounded by percent predicted $\mathrm{FEV}_{1}$, mirroring GOLD recommendations at the time of study set-up. Therefore, patients with worse airflow obstruction had lower frequencies of historically reported moderate or severe exacerbations compared with those with less airflow limitation. Assessing treatment effects by prior exacerbation history subgroups gives insights into the relative effectiveness of ICS/LAMA/LABA, LAMA/LABA and ICS/LABA in these subgroups, but the interpretation of these results could be confounded by additional factors such as blood eosinophil counts. The analysis by blood eosinophil counts relies on the statistical models fitted to this dataset but the thresholds we report for differential effects of therapy are similar to those reported in other studies comparing ICS/LAMA/LABA, ICS/LABA and LAMA/LABA [7, 23].

In summary, these analyses show that FF/UMEC/VI was more effective than both FF/VI and UMEC/VI across multiple COPD end-points. A more complex pattern was apparent for the comparison of FF/VI versus UMEC/VI that varied according to previous exacerbation history. The blood eosinophil count helps discriminate different treatment effects in patients at greater risk of exacerbations (i.e. the frequent moderate and severe subgroups) but had less influence in the single moderate subgroup. These results have 
relevance to clinical practice, as a higher exacerbation risk (based on previous history) and higher blood eosinophil counts favour the use of ICS/LAMA/LABA or ICS/LABA over LAMA/LABA.

Acknowledgements: Editorial support (in the form of writing assistance, assembling figures, collating author comments, grammatical editing and referencing) was provided by Chrystelle Rasamison and Rachel Edwards (Fishawack Indicia Ltd, UK), and was funded by GSK. This study was funded by GSK (study number CTT116855). The funders of the study had a role in the study design, data analysis, data interpretation and writing of the report.

Author contributions: The authors meet criteria for authorship as recommended by the International Committee of Medical Journal Editors, take responsibility for the integrity of the work as a whole, contributed to the writing and reviewing of the manuscript, and have given final approval for the version to be published. All authors had full access to the data in this study and take complete responsibility for the integrity of the data and accuracy of the data analysis. D. M.G. Halpin, M.T. Dransfield and G.J. Criner were involved in acquisition and analysis/interpretation of data. M.K. Han, C.E. Jones, S. Kilbride, P. Lange, D.A. Lomas, F.J. Martinez, D. Singh, and R. Wise were involved in analysis/ interpretation of data. S. Pascoe and D.A. Lipson were involved in the conception/design of the study and analysis/ interpretation of data.

Conflict of interest: D.M.G. Halpin reports other from GlaxoSmithKline, non-financial support from GlaxoSmithKline, during the conduct of the study; personal fees from AstraZeneca, personal fees and non-financial support from Boehringer Ingelheim, personal fees from Chiesi, personal fees from GlaxoSmithKline, personal fees and non-financial support from Novartis, personal fees from Pfizer, outside the submitted work. M.T. Dransfield reports other from GlaxoSmithKline, non-financial support from GlaxoSmithKline, during the conduct of the study; grants from Department of Defense, personal fees and other from Boehringer Ingelheim, personal fees and other from GlaxoSmithKline, other from Novartis, personal fees and other from AstraZeneca, other from Yungjin, personal fees and other from PneumRx/BTG, other from Pulmonx, personal fees from Genentech, other from Boston Scientific, personal fees from Quark Pharmaceuticals, grants from NIH, personal fees from Mereo, grants from American Lung Association, grants from NIH, outside the submitted work. M.K. Han reports other from GlaxoSmithKline, non-financial support from GlaxoSmithKline, during the conduct of the study; personal fees from AstraZeneca, personal fees from Boehringer Ingelheim, other from Novartis, other from Sunovion, personal fees from Mylan, outside the submitted work. E. Jones reports other from GlaxoSmithKline, non-financial support from GlaxoSmithKline, during the conduct of the study; personal fees from GlaxoSmithKline, other from GlaxoSmithKline, outside the submitted work. S. Kilbride reports other from GlaxoSmithKline, non-financial support from GlaxoSmithKline, during the conduct of the study; personal fees from GlaxoSmithKline, other from GlaxoSmithKline, outside the submitted work. P. Lange reports other from GlaxoSmithKline, non-financial support from GlaxoSmithKline, during the conduct of the study; grants and personal fees from GlaxoSmithKline, personal fees from AstraZeneca, personal fees from Boehringer Ingelheim, personal fees from Chiesi, outside the submitted work. D.A. Lipson reports other from GlaxoSmithKline, non-financial support from GlaxoSmithKline, during the conduct of the study; personal fees from GlaxoSmithKline, other from GlaxoSmithKline, outside the submitted work. D.A. Lomas reports personal fees and other from GlaxoSmithKline, non-financial support from GlaxoSmithKline, during the conduct of the study; grants from GlaxoSmithKline, personal fees and other from GlaxoSmithKline, personal fees from Grifols, outside the submitted work. F.J. Martinez reports grants, personal fees and non-financial support from GlaxoSmithKline, non-financial support from GlaxoSmithKline, during the conduct of the study; personal fees and non-financial support from American College of Chest Physicians, personal fees and non-financial support from AstraZeneca, personal fees and non-financial support from Boehringer Ingelheim, non-financial support from ProterrixBio, personal fees from Columbia University, personal fees and non-financial support from ConCert, personal fees and non-financial support from Genentech, personal fees and non-financial support from GlaxoSmithKline, personal fees and non-financial support from Inova Fairfax Health System, personal fees from Integritas, personal fees from MD Magazine, personal fees from Methodist Hospital Brooklyn, personal fees and non-financial support from Miller Communicatinos, personal fees and non-financial support from National Association for Continuing Education, personal fees and non-financial support from Novartis, personal fees from New York University, personal fees and non-financial support from Pearl Pharmaceuticals, personal fees and non-financial support from PeerView Communications, personal fees and non-financial support from Prime Communications, personal fees and non-financial support from Puerto Rican Respiratory Society, personal fees and non-financial support from Chiesi, personal fees and non-financial support from Sunovion, personal fees and non-financial support from Theravance, personal fees from UpToDate, personal fees from WebMD/MedScape, personal fees from Western Connecticut Health Network, other from Afferent/Merck, non-financial support from Gilead, non-financial support from Nitto, personal fees from Patara/Respivant, personal fees from PlatformIQ, personal fees and non-financial support from Potomac, other from Biogen, personal fees and non-financial support from University of Alabama Birmingham, other from Veracyte, non-financial support from Zambon, personal fees from American Thoracic Society, grants from NIH, personal fees and non-financial support from Physicians Education Resource, personal fees from Rockpointe, other from Prometic, personal fees from Rare Disease Healthcare Communications, other from Bayer, other from Bridge Biotherapeutics, personal fees and non-financial support from Canadian Respiratory Network, other from ProMedior, personal fees and non-financial support from Teva, personal fees from France Foundation, personal fees and non-financial support from Dartmouth, outside the submitted work. S. Pascoe reports other from GlaxoSmithKline, non-financial support from GlaxoSmithKline, during the conduct of the study; personal fees from GlaxoSmithKline, other from GlaxoSmithKline, outside the submitted work. D. Singh reports other from GlaxoSmithKline, non-financial support from GlaxoSmithKline, during the conduct of the study; personal fees from GlaxoSmithKline, grants and personal fees from AstraZeneca, grants and personal fees from Boehringer Ingelheim, grants and personal fees from Chiesi, personal fees from Cipla, personal fees from Genentech, grants and personal fees from Glenmark, grants and personal fees from Menarini, grants and personal fees from Mundipharma, grants and personal fees from Novartis, personal fees from Peptinnovate, grants and personal fees from Pfizer, grants and personal fees from Pulmatrix, grants and personal fees from Therevance, grants and personal fees from Verona, outside the submitted work. R. Wise reports personal fees, non-financial support and other from GlaxoSmithKline, during the conduct of the study; grants and personal fees from AstraZeneca / Medimmune / Pearl, grants and personal fees from Boehringer Ingelheim, personal fees from Contrafect, personal fees from Pulmonx, personal fees from Roche, personal fees from Spiration, personal fees from Sunovion, grants 
from Pearl Therapeutics, personal fees from Merck, personal fees from Circassia, personal fees from Pneuma, personal fees from Verona, personal fees from Mylan/Theravance, personal fees from Propeller Health, grants from Sanofi-Aventis, personal fees from AbbVie, grants and personal fees from GSK, outside the submitted work. G.J. Criner reports other from GlaxoSmithKline, non-financial support from GlaxoSmithKline, during the conduct of the study; personal fees from Almirall, personal fees from AstraZeneca, personal fees from Boehringer Ingelheim, personal fees from Chiesi, personal fees from CSA Medical, personal fees from Eolo, personal fees from GlaxoSmithKline, personal fees from HGE Technologies, personal fees from Novartis, personal fees from Nuvaira, personal fees from Olympus, personal fees from Pulmonx, personal fees from Verona, personal fees from NGM Bio, outside the submitted work.

Support statement: This study was funded by GSK (grant: CTT116855, NCT02164513). Funding information for this article has been deposited with the Crossref Funder Registry.

\section{References}

1 Singh D, Agusti A, Anzueto A, et al. Global Strategy for the Diagnosis, Management, and Prevention of Chronic Obstructive Lung Disease: the GOLD science committee report 2019. Eur Respir J 2019; 53: 1900164.

2 Vogelmeier CF, Criner GJ, Martinez FJ, et al. Global Strategy for the Diagnosis, Management, and Prevention of Chronic Obstructive Lung Disease 2017 Report. GOLD Executive Summary. Am J Respir Crit Care Med 2017; 195: 557-582.

3 Han MK, Quibrera PM, Carretta EE, et al. Frequency of exacerbations in patients with chronic obstructive pulmonary disease: an analysis of the SPIROMICS cohort. Lancet Respir Med 2017; 5: 619-626.

4 Hurst JR, Vestbo J, Anzueto A, et al. Susceptibility to exacerbation in chronic obstructive pulmonary disease. N Engl J Med 2010; 363: 1128-1138.

5 Mullerova H, Maselli DJ, Locantore N, et al. Hospitalized exacerbations of COPD: risk factors and outcomes in the ECLIPSE cohort. Chest 2015; 147: 999-1007.

6 Global Initiative for Chronic Obstructive Lung Disease. 2019 Global Strategy for the Diagnosis, Management and Prevention of Chronic Obstructive Pulmonary Disease. Date last updated: January 2019. Date last accessed: April, 2020. http://goldcopd.org/gold-reports/.

7 Bafadhel M, Peterson S, De Blas MA, et al. Predictors of exacerbation risk and response to budesonide in patients with chronic obstructive pulmonary disease: a post-hoc analysis of three randomised trials. Lancet Respir Med 2018; 6: 117-126.

8 Pavord ID, Lettis S, Locantore N, et al. Blood eosinophils and inhaled corticosteroid/long-acting beta-2 agonist efficacy in COPD. Thorax 2016; 71: 118-125.

9 Roche N, Zysman M, Burgel PR. Blood eosinophil counts as a guide for COPD treatment strategies. Lancet Respir Med 2018; 6: 78-80.

10 Siddiqui SH, Pavord ID, Barnes NC, et al. Blood eosinophils: a biomarker of COPD exacerbation reduction with inhaled corticosteroids. Int I Chron Obstruct Pulmon Dis 2018; 13: 3669-3676.

11 Lipson DA, Barnhart F, Brealey N, et al. Once-daily single-inhaler triple versus dual therapy in patients with COPD. N Engl J Med 2018; 378: 1671-1680.

12 Pascoe SJ, Lipson DA, Locantore N, et al. A phase III randomised controlled trial of single-dose triple therapy in COPD: the IMPACT protocol. Eur Respir J 2016; 48: 320-330.

13 Pascoe S, Barnes N, Brusselle G, et al. Blood eosinophils and treatment response with triple and dual combination therapy in chronic obstructive pulmonary disease: analysis of the IMPACT trial. Lancet Respir Med 2019; 7: 745-756.

14 Vogelmeier CF, Chapman KR, Miravitlles M, et al. Exacerbation heterogeneity in COPD: subgroup analyses from the FLAME study. Int J Chron Obstruct Pulmon Dis 2018; 13: 1125-1134.

15 Papi A, Vestbo J, Fabbri L, et al. Extrafine inhaled triple therapy versus dual bronchodilator therapy in chronic obstructive pulmonary disease (TRIBUTE): a double-blind, parallel group, randomised controlled trial. Lancet 2018; 391: 1076-1084.

16 Singh D, Papi A, Corradi M, et al. Single inhaler triple therapy versus inhaled corticosteroid plus long-acting beta2-agonist therapy for chronic obstructive pulmonary disease (TRILOGY): a double-blind, parallel group, randomised controlled trial. Lancet 2016; 388: 963-973.

17 Vestbo J, Papi A, Corradi M, et al. Single inhaler extrafine triple therapy versus long-acting muscarinic antagonist therapy for chronic obstructive pulmonary disease (TRINITY): a double-blind, parallel group, randomised controlled trial. Lancet 2017; 389: 1919-1929.

18 Calverley PMA, Tetzlaff K, Vogelmeier C, et al. Eosinophilia, frequent exacerbations, and steroid response in chronic obstructive pulmonary disease. Am J Respir Crit Care Med 2017; 196: 1219-1221.

19 Papi A, Kostikas K, Wedzicha JA, et al. Dual bronchodilation response by exacerbation history and eosinophilia in the FLAME study. Am J Respir Crit Care Med 2018; 197: 1223-1226.

20 Kon SS, Canavan JL, Jones SE, et al. Minimum clinically important difference for the COPD Assessment Test: a prospective analysis. Lancet Respir Med 2014; 2: 195-203.

21 Jones PW. St. George's Respiratory Questionnaire: MCID. COPD 2005; 2: 75-79.

22 Wedzicha JA, Banerji D, Chapman KR, et al. Indacaterol-glycopyrronium versus salmeterol-fluticasone for COPD. N Engl J Med 2016; 374: 2222-2234.

23 Ferguson GT, Rabe KF, Martinez FJ, et al. Triple therapy with budesonide/glycopyrrolate/formoterol fumarate with co-suspension delivery technology versus dual therapies in chronic obstructive pulmonary disease (KRONOS): a double-blind, parallel-group, multicentre, phase 3 randomised controlled trial. Lancet Respir Med 2018; 6: 747-758. 